\title{
BMJ Global Health Vertical and horizontal equity of funding for malaria control: a global multisource funding analysis for 2006- 2010
}

\author{
Eliana Barrenho, ${ }^{1,2}$ Marisa Miraldo, ${ }^{1,2}$ Mujaheed Shaikh, ${ }^{3}$ Rifat Atun ${ }^{4}$
}

To cite: Barrenho E, Miraldo M, Shaikh $\mathrm{M}$, et al. Vertical and horizontal equity of funding for malaria control: a global multisource funding analysis for 2006-2010. BMJ Glob Health 2017;2:e000496. doi:10.1136/ bmjgh-2017-000496

Handling editor Seye Abimbola

- Additional material is published online only. To view please visit the journal online (http://dx.doi.org/10.1136/ bmjgh-2017-000496).

Received 26 July 2017 Revised 13 0ctober 2017 Accepted 8 November 2017

\section{(a) CrossMark}

'Department of Management, Imperial College Business School, Imperial College London, London, UK

${ }^{2}$ Centre for Health Economics and Policy Innovation, Imperial College Business School, Imperial College London, London, UK

${ }^{3}$ Health Economics and Policy Division, Vienna University of Economics and Business, Vienna, Austria

${ }^{4}$ Harvard TH Chan School of Public Health, Harvard University, Boston, Massachusetts, USA

Correspondence to Dr Marisa Miraldo; m.miraldo@imperial.ac.uk

\section{ABSTRACT}

Background International and domestic funding for malaria is critically important to achieve the Sustainable Development Goals. Its equitable distribution is key in ensuring that the available, scarce, resources are deployed efficiently for improved progress and a sustained response that enables eradication.

Methods We used concentration curves and

concentration indices to assess inequalities in malaria funding by different donors across countries, measuring both horizontal and vertical equity. Horizontal equity assesses whether funding is distributed in proportion to health needs, whereas vertical equity examines whether unequal economic needs are addressed by appropriately unequal funding. We computed the Health Inequity Index and the Kakwani Index to assess the former and the latter, respectively. We used data from the World Bank, Global Fund, Unicef, President's Malaria Initiative and the Malaria Atlas Project to assess the distribution of funding against need for 94 countries. National gross domestic product per capita was used as a proxy for economic need and 'population-at-risk' for health need.

Findings The level and direction of inequity varies across funding sources. Unicef and the President's Malaria Initiative were the most horizontally inequitable (pro-poor). Inequity as shown by the Health Inequity Index for Unicef decreased from $-0.40(P<0.05)$ in 2006 to $-0.25(P<0.10)$ in 2008 , and increased again to $-0.58(P<0.01)$ in 2009. For President's Malaria Initiative, it increased from -0.19 ( $P>0.10)$ in 2006 to $-0.38(P<0.05)$ in 2008 , and decreased to $-0.36(P<0.10)$ in 2010. Domestic funding was inequitable (pro-rich) with inequity increasing from $0.28(\mathrm{P}<0.01)$ in 2006 to 0.39 $(P<0.01)$ in 2009, and then decreasing to $0.22(P<0.10)$ in 2010. Funding from the World Bank and the Global Fund was distributed proportionally according to need. In terms of vertical inequity, all sources were progressive: Unicef and the President's Malaria Initiative were the most progressive with the Kakwani Indices ranging from $-0.97(\mathrm{P}<0.01)$ to -1.29 $(\mathrm{P}<0.01)$, and $-0.90(\mathrm{P}<0.01)$ to $-1.10(\mathrm{P}<0.01)$, respectively. Conclusion Our results suggest that external funding of malaria treatment tends to be allocated to countries with higher health and economic need but not in proportion to their relative health need and income when compared to other countries. While malaria eradication might require funders to disproportionally allocate funding that goes beyond (financial and health) need, our analysis

\section{Key questions}

What is already known about this topic?

- Previous studies hint at inequitable distribution of malaria funding across countries.

- However, nothing is known about the level of inequality and of (horizontal and vertical) inequity in malaria funding.

What are the new findings?

- Inequity of funding in relation to both health and economic need varies with the source of malaria funding in 2006-2010.

- External funding from Unicef and President's Malaria Initiative was the most horizontally inequitable (pro-poor), while domestic funding was inequitable (pro-rich) in all years. In terms of vertical equity, all external sources of funding were progressive: Unicef and President's Malaria Initiative were the most progressive.

Recommendations for policy

- Regular assessments of need and greater coordination among donors are necessary for equitable resource allocation, to improve and sustain progress with malaria control and elimination.

- Therefore, measuring both vertical and horizontal equity can inform how global malaria funding can be efficiently allocated.

- These are crucial in the context of the funding shortfall of $\$ 5.1$ billion each year to combat malaria, as estimated by the World Health Organization.

highlights that funders might potentially be targeting in excess certain countries. Regular assessments of need and greater coordination among donors are necessary for equitable resource allocation, to improve and sustain progress with malaria control and elimination.

\section{INTRODUCTION}

Controlling malaria is a global health priority, and a target for the Sustainable Development Goal 3 (SDG3) to eliminate malaria by 2030. Despite a reduction in malaria case incidence 
of $41 \%$ and mortality of $62 \%$ since 2000 , an estimated 2.8 billion people globally are still at risk of malaria and 1.1 billion are at high risk of developing the disease. ${ }^{2}$ In low- and middle-income countries (LMICs) where malaria is endemic, SDG3 are unlikely to be achieved, with malaria imposing substantial health and economic burden on the societies it affects-each year Africa loses around $£ 8$ billion due to malaria. ${ }^{34}$ In addition to the mortality and morbidity it causes in adults and children, malaria adversely affects educational attainment of children, and consequently, reduces their life chances. ${ }^{5}$ Countries affected by malaria experience major barriers to achieving the demographic dividend-so critical for sustainable development. ${ }^{6}$

Most of the affected countries are under-resourced to effectively fight malaria and need sustained international funding. ${ }^{7}$ International funding plays a critical role in alleviating the burden of malaria and has significantly increased $^{8}$ from $\$ 149$ million in 2000 to $\$ 1.2$ billion in 2008 and to $\$ 2.3$ billion in $2011 .{ }^{39}$ In 2013 , however, while worldwide funding for malaria control and elimination had increased to $\$ 2.7$ billion, international investment declined to $\$ 2.18$ billion. ${ }^{10}$ The funding in 2013 was well short of the $\$ 5.1$ billion needed each year, as estimated by the World Health Organization (WHO) ${ }^{10}$ Since 2008, the economic crisis and austerity measures imposed by donor countries have resulted in stagnation and decline in international funding. ${ }^{8}$ Hence, there is an imperative to deploy available resources efficiently and equitably to ensure sustainability of the malaria response ${ }^{8}$ and to ensure funding shortfall does not lead to the upsurge of malaria. $^{3}$

While the adequacy of funding is critical, its equitable distribution is equally important to ensure resources are efficiently allocated to those that need them the most. Both vertical equity (unequal treatment of unequals in a fair sense) and horizontal equity (equal treatment for equal need) are important when analysing the adequacy of malaria funding. Equity analysis allows assessing whether funding is distributed according to health need and country affordability of malaria treatment. Yet, few studies have explored (beyond descriptive analysis) equity of funding for malaria globally.

Snow et al. ${ }^{7}$ assessed the adequacy of malaria funding and find that, while international funding for malaria increased substantially since 2007, African countries were the major recipients of international assistance and countries where Plasmodium vivax continues to pose a threat did not receive enough funding. Assistance was found to be inadequate for 50 countries, and donor funding did not correlate with economic status of the country. Similarly, Pigott $e t a l^{8}$ concluded that few countries with large populations at risk receive adequate funding. The observed existence of inadequacy presents concerns with respect to the achievement of global malaria targets. While both studies are important contributions towards understanding the nature of international funding and drawing attention to inequalities in funding based on both biological and economic need, they do not measure inequity in malaria funding. In this paper, we build on the extant studies by measuring both horizontal and vertical equity in malaria funding. We compare inequity at cross-country level in domestic (Government) funding (GovStats in figures/tables) and across the major international sources of malaria funding, namely the President's Malaria Initiative (PMI), the World Bank, Unicef and the Global Fund to Fight AIDS, Tuberculosis and Malaria (Gfatm in figures/tables).

\section{METHODS AND DATA \\ Data}

The dataset used covered 94 countries across different world regions (Americas, Asia and Africa) from 2006 to 2010. Data on funding were obtained from both international donors and government funds. Data for gross domestic product (GDP) per capita are from the World Bank data. Absolute values for health indicators as proxied by stable and total population at risk were calculated as outlined in Pigott et al. ${ }^{8}$

Data on external funding by country were obtained from several sources-the PMI data were taken from the fifth annual report up to financial year 2010 and the Malaria Operational Plans for year 2011. ${ }^{11}$ The Global Fund data were based on the organisation's Country Portfolios ${ }^{\mathrm{i}, 12}{ }^{12}$ Unicef data were obtained from the Creditor Reporting System from the Organization for Economic Co-operation and Development (OECD) statistics ${ }^{13}$ and the World Bank figures were taken from the Booster Program grants listing. ${ }^{14}$ We used data on 'disbursements' instead of 'commitments' since the former presents a more accurate picture of the actual funding made available to countries. We had data available on disbursements from the Global Fund ${ }^{12}$ and $\mathrm{PMI}^{11}$ up to 2009, and from the World Bank and Unicef for the period between 2006 and 2008. ${ }^{13}$

Data for domestic funding were obtained from grant proposals to the Global Fund since such reports are considered valid and unbiased, and allow us avoiding double counting as they provide a detailed account of malaria budgets. Data for countries that did not request Global Fund support were obtained from the World Malaria Report 2011. ${ }^{15}$ The figures for domestic funding and external disbursements were added to obtain total funding received (henceforth TotalReceived).

Data for GDP from 2006 to 2010 were taken from the World Bank Development Indicators Data. ${ }^{16}$ The data are expressed in per capita constant US\$ adjusted for purchasing power parity. ${ }^{\mathrm{i}}$

\footnotetext{
${ }^{\mathrm{i}}$ Country portfolios refer to the different areas that the Global Fund invests in each country. For example, the investments made into HIV, tuberculosis and malaria. The portfolio here is the collection of funds received by each country devoted to malaria eradication and prevention.

ii It could be argued that GDP per capita is an imperfect measure of "financing need" as income per capita might not be a good proxy for how poor a country is if income distribution is skewed within a country.
} 
We used total 'population-at-risk' of malaria transmission as a proxy for health need. As outlined in Pigott et al. ${ }^{8}$ we used figures for populations at risk of stable transmission (StablePAR) and total (including stable and unstable) transmission (TotalPAR) of Plasmodium (P.) falciparum and Plasmodium vivax. These were calculated using the population at risk of transmission for both $P$. falciparum and $P$ vivax in 2010, described in detail in Pigott $e t a l .{ }^{8}$ and produced by Malaria Atlas Project (MAP). ${ }^{17} 18$

The definition of health need imposes challenges, as thoroughly discussed in the literature, ${ }^{19-21}$ and ultimately rests on value judgements. ${ }^{22}$ It would be desirable to have measures of population health needs evaluated through health losses attributable to malaria and its associated risks. Previous literature has used different measures such as the proportion of people affected at a given point in time, proportion of population by endemicity, adult and child malaria deaths, and WHO estimates of "population-at-risk ${ }^{9}{ }^{9}$ However, these data are either low resolution (at a crude geographic level), based on inaccurate case reports, or have large uncertainty. We used data on 'population-at-risk' of malaria, readily available for 94 countries from MAP. ${ }^{83}$ The MAP data are based on a hugely expanded evidence-base, are of high resolution and are comparatively less uncertain. ${ }^{83}$

\section{Methods}

Inequalities were measured through concentration curves (CCs) and concentration indices (CIs). ${ }^{24}$ While these analyses are useful to assess how funding is distributed across countries, inequalities observed through the concentration curves and indices must not be directly interpreted as inequity. Variation in disbursements due to differences in healthcare need or affordability might be a legitimate source of inequality. Those countries with greater burden of disease legitimately ought to be entitled to higher disbursements compared with those with lower disease burden. Therefore, to determine the extent of inequity a comparison needs to be made between the distributions of need (malaria burden) with the distribution of malaria funding across income deciles: we refer to this concept as horizontal inequity.

The concentration curves in this context plot the cumulative proportion of countries ranked by living standards (proxied by GDP per capita) against the cumulative proportion of need (proxied by TotalPAR and StablePAR) and expenditure in malaria (proxied by per capita funding).

\footnotetext{
Additionally, it might also not be indicative of how much a country spends on healthcare. However, GDP per capita is widely used as a proxy for income in country-level analysis as it is readily available and has been found to correlate with other proxies of income distribution within countries as well as with healthcare expenditure. While these are legitimate concerns, we believe that these are not strong limitations in our analysis since we are looking at distributions across countries. Therefore, while it can be argued that GDP per capita can be an imperfect proxy of "financing need", at most we are incurring a measurement error rather than a systematic bias. Our analysis would only be distorted systematically if inequality within countries would correlate with the ranking of countries according to GDP per capita.
}

The extent of horizontal inequity is assessed by measuring the Health Inequity Index (HII) that is computed as the difference between the concentration index for healthcare expenditure (used as a proxy for healthcare; in our case malaria funding) and that for health need. ${ }^{2425}$

It can also be argued that countries with lower domestic affordability for treatment legitimately ought to be entitled to higher disbursements compared with richer countries. Therefore, to determine the extent of vertical inequity we compared the concentration curve for GDP per capita (Lorenz curve) with the concentration curve of malaria funding across income deciles. Vertical inequity was then measured through the Kakwani Index (KI), which is the most widely used measure of progressivity in financing of a health system. ${ }^{20}{ }^{2526}$ The KI allows assessing the extent to which countries with unequal ability to finance malaria control and elimination receive appropriately unequal funding from international donors. More specifically, the concept of vertical equity helps to identify whether a particular funding source is 'progressive' (i.e. pro-poor), regressive (i.e. pro-rich) or proportional (i.e. aligned to economic status). ${ }^{\text {iii }}$ Further details on these methods can be found in the online supplementary material appendix.

\section{RESULTS}

Online supplementary figure A1 shows the total funding disbursed by source of funding from 2006 to 2010. The Global Fund has consistently been one of the highest donors, especially in 2009 and 2010. The lowest funds disbursed were by Unicef across all years. Domestic funding was the highest source of funding in 2006, 2007 and 2008. Online supplementary table A1 presents descriptive statistics in detail.

Online supplementary figures B1-B6 show the average funding for each source (overall and by year), with countries grouped by income quintiles (1=lowest to $5=$ highest). Overall the data suggest that countries in the lowest income quintile (first quintile) receive substantially higher disbursements compared with those in higher quintiles (online supplementary figure B1) . However, countries in the second lowest quintile receive slightly lower disbursements than countries in the third quintile. Moreover, while total funding seems to be progressive (decreases as income quintile increases) in 2006 and 2010, the picture is mixed for the other years.

To consider health need, and therefore make more definitive conclusions regarding inequality in funding, we rely on the concentration curves and indices presented in the next section.

\footnotetext{
iii It could be argued that given there is a close relationship between disease burden and GDP, the vertical and horizontal equity analysis tell conceptually the same construct. However, while GDP and disease burden are correlated, these are not perfectly correlated $(-0.19(\mathrm{P}<0.01)$ for TotalPAR and -0.06 ( $\mathrm{P}>0.10)$ for StablePAR), and therefore the two analyses capture different inequality and inequity constructs.
} 


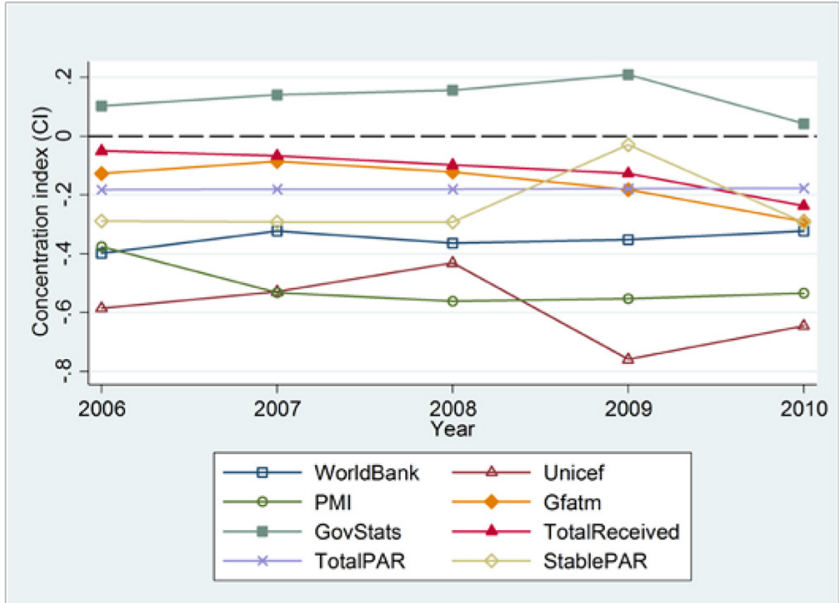

Figure 1 Concentration Index by funding source.

\section{Inequality, Concentration Curves and Indices}

Online supplementary figures A2-A6 show CCs for each source of funding per year of the analysis. For example, in terms of the distribution of health need (i.e. malaria burden), the CCs for both StablePAR and TotalPAR are above the equality line throughout the distribution (online supplementary figure A2), suggesting that poorer countries exhibit higher proportions of affected populations than richer countries. For example, in 2006, the curve for TotalPAR shows that approximately $50 \%$ of the malaria burden was attributed to the $40 \%$ poorest countries. Similarly, $75 \%$ of the malaria burden was concentrated in the $60 \%$ poorest countries. This pattern is verified across all years (online supplementary figures A3-A6), and the share of malaria burden remains relatively stable across all years. This is confirmed by the statistically significant $\mathrm{CIs}(\mathrm{P}<0.01$ for all years; online supplementary table A2) that are negative throughout without large differences in magnitude from one year to another.

In what follows, we discuss inequality in funding by assessing the distribution of funding from each source. Online supplementary figures A2-A6 illustrate concentration curves for the different sources of funding and the Lorenz curve for the years 2006-2010.

In all years, the Lorenz curve lies below the equality line, highlighting high inequality (pro-rich) in the income distribution across countries for all years (e.g., $60 \%$ of the poorest have only around $20 \%$ of the global income in all years). Similarly, domestic funding is below the equality line in all years, indicating pro-rich inequality (except in 2010 where it crosses the equality line at several points of the distribution). All the other sources of funding are above the equality line, indicating pro-poor inequality in malaria funding with the exception of the World Bank, which is below the equality line in the first quartile of the distribution in 2007 and 2010. Similarly, TotalReceived funding crosses the equality line and lies below it in the very last part of the distribution for 2006, 2007 and 2008. Overall, one can infer from the curves that PMI and Unicef exhibit the highest level of pro-poor inequality along with both sources showing their CCs farthest from the equality line in 2009. In fact, all sources of funding, except for the World Bank, show the largest inequalities in this year. The World Bank shows pro-poor inequality; however, on careful observation it can be seen that for most years its CCs are very close to the equality line in the first one-third of the distribution, and then moves further away. Together, these findings suggest that for the subgroup of countries at the bottom of the income distribution funding tends to be distributed according to income, while for the upper part of the income distribution the distribution of funding is pro-poor.

These results are confirmed by the CIs (online supplementary table A2 and figure $\left.1^{\text {iv }}\right)$. For World Bank $(\mathrm{P}<0.05$ for years 2006 and 2008, and $\mathrm{P}<0.10$ for the rest), Unicef $(\mathrm{P}<0.01$ for all years $)$ and $\mathrm{PMI}(\mathrm{P}<0.01$ for all years except 2006 when $\mathrm{P}<0.05$ ), the indices are always negative, implying that these funding sources exhibit pro-poor (countries) inequality. In terms of magnitude of the inequality, the indices confirm the concentration curves analysis. Across most years, Unicef and PMI exhibit more pro-poor inequality. The CIs for domestic funding are positive $(\mathrm{P}<0.05$ for 2009$)$, indicating pro-rich inequality for this source of funding. However, it is not statistically significant in other years. For the Global Fund, the CIs are negative in all years, suggesting that this source of funding is pro-poor unequal in these years, but is statistically significant only in $2010(\mathrm{P}<0.01)$.

While it is interesting to understand the degree of pro-rich or pro-poor inequality per funding source, equally interesting is to know whether the concentration indices are significantly different between donors, that is, whether one funding source is significantly more unequal compared with another donor in a particular year. We use dominance testing, a standard method in this type of analysis to compare significant differences between two concentration curves. We explain the method in detail in the supplementary material. Online supplementary tables $\mathrm{A} 3 \mathrm{a}-\mathrm{A} 3 \mathrm{e}$ and $\mathrm{A} 4 \mathrm{a}-\mathrm{A} 4 \mathrm{f}$ show the results of the dominance testing. Overall, we see that Unicef dominates over most funding sources in all years, indicating that it is significantly more pro-poor unequal than most other sources of funding (online supplementary tables A3a-A3e). We do not find any significant within-donor differences in the index (online supplementary tables A4a-A4f).

\section{Health Inequity Index}

The HII results are presented in the online supplementary table A5, and its evolution over time in figure 2.

\footnotetext{
${ }^{\text {iv }}$ Figure 1 shows the inequality trend for each source of funding from 2006 to 2010 . The horizontal line (0) represents the line of equality. Note that in the concentration curve figures (online supplementary figures A2-A6), a curve above (below) the equality line means a negative (positive) concentration index and thus pro-poor (pro-rich) inequality. In figure 1 , however, we directly present the concentration index, hence a negative concentration index equivalently means pro-poor inequality but will lie below the equality line $(0)$ and vice versa.
} 


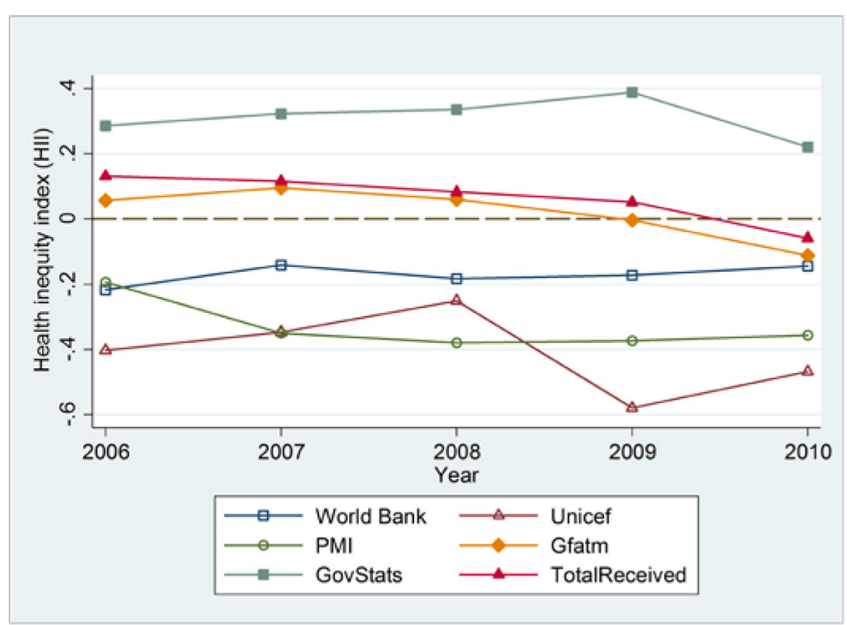

Figure 2 Health Inequity Index by funding source.

Unicef and PMI are the most horizontally inequitable (pro-poor) sources of funding as shown by the negative index. Unicef is the most inequitable (pro-poor) with statistically significant indices in all years $(\mathrm{P}<0.05$ for 2006 , 2007 and 2010; $\mathrm{P}<0.10$ for 2008 and $\mathrm{P}<0.01$ for 2009). PMI is statistically significantly negative (i.e. inequitable pro-poor $)$ in all years $(\mathrm{P}<0.05)$, except in the year 2006 when it is not significant. Domestic funding is positive and statistically significant in all years, suggesting horizontal inequity pro-rich $(\mathrm{P}<0.01$ in all years except 2010 when $\mathrm{P}<0.10)$.

\section{Robustness Check}

As a robustness check, we have also estimated the CIs and the HII using funding divided by total population-at-risk' (TotalPAR) instead of funding per capita. The online supplementary tables A6-A7 present these results with the CIs and P-values. For the CIs, the results remain qualitatively the same with the exception of the CI for domestic funding that is now significant $(\mathrm{P}<0.01$ in all years) and for total funding received which is now significantly pro-rich in all years. With respect to the HII, the results are qualitatively the same as before.

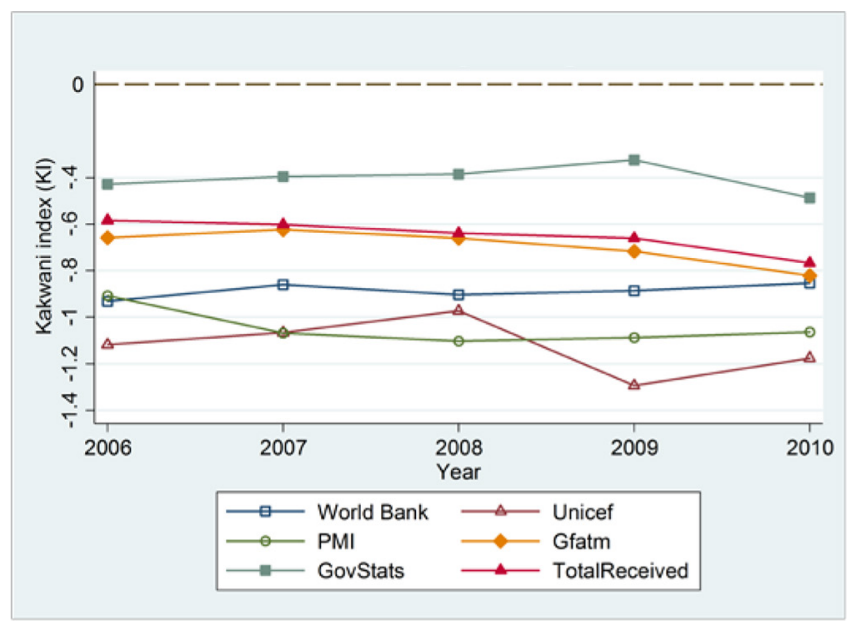

Figure 3 Kakwani Index by funding source.

\section{Progressivity and the Kakwani Index}

Across all years (2006-2010), the Lorenz curve envelopes and lies below the concentration curves for all sources of funding (see online supplementary figures A2-A6), suggesting that all sources of funding tend to be progressive in nature. The KIs and the corresponding 95\% confidence intervals and P-values in the online supplementary table A8 confirm these results. Overall, it can be seen that for all sources of funding the index is negative and significant $(\mathrm{P}<0.01)$, indicating progressivity in funding. If one compares the magnitude of the KIs, the results suggest that Unicef and PMI are the most progressive sources of funding, while domestic funding is the least progressive source of funding in all the years. Figure 3 shows the KIs as a time trend graph.

\section{DISCUSSION}

Despite substantial increases in international donor assistance to control and eliminate malaria since 2000, international and domestic funding falls short of the required level estimated by the WHO. ${ }^{7}$ The SDG3 are unlikely to be achieved without effective control and elimination of malaria, given the substantial health and economic burden it imposes on the affected societies.

Since the global economic crisis of 2008, adequacy of funding for malaria control and elimination has received substantial attention due to declined funding. Equity in funding, although explored in some earlier studies, ${ }^{67}$ has, however, received comparatively less attention.

In times of economic uncertainty and austerity, funding must be targeted at the most vulnerable groups in terms of both health risk and economic need ${ }^{7}$ to ensure scarce resources reach where they should. Such strategic decisions ought to be informed by a routine assessment of vertical and horizontal equity of funding distribution.

This study is the first to analyse equity of malaria financing from different funding sources, with respect to health need and economic need. The study uses, for the first time, HII and KI to quantify the degree of inequity in malaria funding in total and by source of funding at a cross-country level.

We find that while inequity in funding in relation to both health and income exists, some external funding sources are more inequitable than others. For example, for both horizontal and vertical equity, Unicef and PMI are the most inequitable (pro-poor) sources of funding. The HII (measuring horizontal inequity) for Unicef decreased from $-0.40(\mathrm{P}<0.05)$ in 2006 to $-0.25(\mathrm{P}<0.05)$ in 2008, and increased again to $-0.58(\mathrm{P}<0.01)$ in 2009 . For PMI, the HII increased from $-0.19(\mathrm{P}>0.10)$ in 2006 to $-0.38(\mathrm{P}<0.05)$ in 2008 , and decreased to $-0.36(\mathrm{P}<0.10)$ in 2010. Unicef and PMI were the most progressive with KIs ranging from $-0.97(\mathrm{P}<0.01)$ to $-1.29(\mathrm{P}<0.10)$, and $-0.90(\mathrm{P}<0.01)$ to $-1.10(\mathrm{P}<0.01)$, respectively. The World Bank and the Global Fund, however, show funding to be proportionally distributed according to need. Similarly, total funding received is also proportionally distributed. 
The assessment of domestic funding indicates it is a progressive funding source and horizontally inequitable but in favour of the richer countries (i.e. pro-rich), with inequity increasing from $0.28(\mathrm{P}<0.01)$ in 2006 to 0.39 $(\mathrm{P}<0.01)$ in 2009 , and then decreasing to $0.22 \quad(\mathrm{P}<0.10)$ in 2010. This finding is not surprising given that richer countries can afford greater levels of funds for their own malaria programme compared with poorer countries. High-income countries simply have more fiscal space for expenditure on health in general, and this reflects such overall trends in government health expenditure. This finding, however, highlights the need for international funding to be distributed more strategically in order to counterbalance the lack of affordability in poorer countries.

Overall, our results suggest that while external funding of malaria treatment tends to be allocated to countries with higher health and economic need it is not allocated in proportion to countries' relative need.

The normative assessment on the adequacy of disproportionally favouring higher (health and financial) need countries would require consensus on a global welfare function and preferences against which distribution of funding could be assessed.

However, if such global preferences are aligned with funding being distributed in proportion to relative need, our results suggest that there should be better coordination between funders. Indeed, the existing donor allocation mechanisms do not involve international coordination across funders. Instead, funders individually negotiate with each country, leading to disproportionate allocation of funding that does not reflect relative need across countries.

Coordination across funders, combined with a shared vision of what global preferences ought to be, can potentiate resource allocation mechanisms that enable equitable use of global funding across countries. Such allocation mechanisms ought to involve a thorough assessment of global health needs, how these are distributed across different countries, the progressivity of the different funding sources and how countries compare in terms of their domestic financial ability to address current and future needs. Amid the widely recognised important principles of equity underpinning resource allocation, its usage is still almost entirely confined to the allocation of resources within higher-income countries, with few LMICs, as well as international donors, using equity as a criterion for resource allocation. ${ }^{27} 28$

Our study has three limitations that might affect the results and their interpretation. First, the analysis assumes that StablePAR and TotalPAR are legitimate sources of variation in funding. To the extent that these capture need accurately and fully, the interpretation of the inequality and inequity holds. Further, these indicators represent 'population-at-risk' and, therefore, might overestimate the number of people affected by malaria and, hence, malaria burden. Second, the data used are at the country level and, hence, we are unable to assess how funding is distributed internally across the different subgroups of each national population. As a result, we are unable to assess inequalities within country due to income, need and other socioeconomic determinants, all of which are instrumental in the impact of the disbursements. We use GDP per capita at the country level to rank countries, which might mask inequalities in income distribution within countries. Given that the malaria burden might be strongly correlated with income, we might be underestimating inequality in funding.

Third, ideally, we would include more recent information in our analysis. However, we have not been successful in gathering complete data on all variables we need for a broader range of years. In particular, data on the "population-at-risk' that we use in this paper from the Malaria Atlas Project are available largely only for African countries after 2010.

The World Malaria Report $2016^{2}$ reports decreasing trends from 2011 to 2015 in total funding. While the extrapolation of our results into more recent years would require better data on the distribution of funding and need across countries, our results highlight that, in the context of reduced funding, the equitable distribution of the available funding becomes all the more important.

Further research would also help in illuminating important policy questions. First, with data that are more refined further research can decompose the inequity in malaria funding to identify its legitimate and illegitimate sources, and assess the role of each of these sources in explaining and addressing the burden of malaria. Second, it would also be important to assess the strategies and processes behind external donor decision-making concerning funding allocation in order to identify the barriers and enablers towards improving equity in malaria funding. Third, even if malaria funding were equitably distributed across countries, it would be important to assess how equitable the distribution of that funding is within each country. That analysis requires detailed within-country individual data on socioeconomic characteristics (such as income, education, health, among others) along with detailed data on deployment of funding within a country and across its population.

Acknowledgements We would like to thank Professor Owen O'Donnell and Dr. Brendan Walsh for their comments to previous versions of this analysis. We also thank the anonymous referees for several invaluable comments that helped improving this paper.

Contributors All authors contributed to the analysis and writing up of the paper. MS and MM collected the data.

Competing interests None declared.

Provenance and peer review Not commissioned; externally peer reviewed.

Data sharing statement Data are available from open sources, namely: i) data on external funding by country was obtained from: PMl fifth annual report, the Malaria Operational Plans, The Global Fund Country Portfolios, the Creditor Reporting System from OECD statistics, and the Booster Program grants listing; ii) data for domestic funding was obtained from grant proposals to the Global Fund and the World Malaria Report 2011; iii) GDP data were taken from the World Bank Development Indicators Data; and 'population-at-risk' of malaria transmission were taken from the Malaria Atlas Project. 
Open Access This is an Open Access article distributed in accordance with the Creative Commons Attribution Non Commercial (CC BY-NC 4.0) license, which permits others to distribute, remix, adapt, build upon this work non-commercially, and license their derivative works on different terms, provided the original work is properly cited and the use is non-commercial. See: http://creativecommons.org/ licenses/by-nc/4.0/

(c) Article author(s) (or their employer(s) unless otherwise stated in the text of the article) 2017. All rights reserved. No commercial use is permitted unless otherwise expressly granted.

\section{REFERENCES}

1. O'Meara WP, Mangeni JN, Steketee R, et al. Changes in the burden of malaria in sub-Saharan Africa. Lancet Infect Dis 2010;10:545-55.

2. World Health Organization. World Malaria Report 2014. Geneva: World Health Organization, 2014

3. National Audit Office. Malaria. London: National Audit Office, 2013.

4. Sachs J, Malaney P. The economic and social burden of malaria. Nature 2002;415:680-5

5. Fink G, Olgiati A, Hawela M, et al. Association between early childhood exposure to malaria and children's pre-school development: evidence from the Zambia early childhood development project. Malar J 2013;12:12.

6. Canning D, Raja S, Yazbeck AS, eds. Africa's demographic transition: Dividend or disaster? Washington:DC: World Bank Publications, 2015.

7. Snow RW, Okiro EA, Gething PW, et al. Equity and adequacy of international donor assistance for global malaria control: an analysis of populations at risk and external funding commitments. The Lancet 2010;376:1409-16.

8. Pigott DM, Atun R, Moyes CL, et al. Funding for malaria control 2006-2010: a comprehensive global assessment. Malar J 2012;11:246

9. Murray CJL, Rosenfeld LC, Lim SS, et al. Global malaria mortality between 1980 and 2010: a systematic analysis. The Lancet 2012;379:413-31.

10. World Health Organization. World Malaria Report 2016. Geneva: WHO, 2016.

11. The President's Malaria Initiative. The Fifth Annual Report to Congress. Washington: PMI, 2011.

12. Global Fund to Fight AIDS, Tuberculosis and Malaria. Grant data 2013. https://www.theglobalfund.org/en/portfolio/country/list/?loc= (accessed 7 Apr 2017).
13. Organisation for Economic Co-operation and Development. Creditor Reporting System. 2013 http://stats.oecd.org/qwids

14. World Bank. Booster program for malaria control. $2013 \mathrm{http}: / /$ projects.worldbank.org/P097921/malaria-control-booster-project? lang=en (accessed 7 Apr 2013).

15. World Health Organization. World Malaria Report 2011. Geneva: WHO, 2011.

16. World Bank. World Development indicators. http://data.worldbank. org/data-catalog/world-development-indicators (accessed $7 \mathrm{Apr}$ 2013).

17. MAP: Malaria Atlas Project. University of Oxford: Oxford. www.map. ox.ac.uk

18. Hay SI, Snow RW. The Malaria Atlas Project: developing global maps of malaria risk. PLoS Med 2006;3:e473.

19. Culyer AJ, Wagstaff A. Equity and equality in health and health care. $\checkmark$ Health Econ 1993;12:431-57.

20. Wagstaff $A$, Van Doorslaer E. Equity in health care finance and delivery. In: Culyer AJ, Newhouse JP, eds. Handbook of Health Economics. Amsterdam: Elsevier, 2000:1803-62.

21. Williams A, Cookson R. Equity in Health. In: Culyer AJ, Newhouse JP, eds. Handbook of Health Economics. Amsterdam: Elsevier, 2000:1863-910.

22. Gravelle H, Morris S, Sutton M. Economic studies of equity in the consumption of health care. In: Jones A, ed. The Elgar Companion to Health Economics. Cheltenham: Edward Elgar Publishing, 2006:193-204.

23. Gething PW, Patil AP, Smith DL, et al. A new world malaria map: Plasmodium falciparum endemicity in 2010. Malar J 2011;10:378.

24. Wagstaff A, O'Donnell O, Van Doorslaer E, et al. Analyzing health equity using household survey data: a guide to techniques and their implementation. Washington, DC: World Bank Publications, 2008.

25. Kakwani N, Wagstaff A, van Doorslaer E. Socioeconomic inequalities in health: Measurement, computation, and statistical inference. J Econometrics 1997;77:87-103.

26. Wagstaff A, Van Doorslaer E, Paci P. Equity in the finance and delivery of health care: some tentative cross-country comparisons. Oxford Review of Economic Policy 1989;5:89-112.

27. Revill P, Asaria M, Phillips A, et al. WHO decides what is fair? International HIV treatment guidelines, social value judgements and equitable provision of lifesaving antiretroviral therapy. York: Centre for Health Economics, University of York, 2014. CHE Research Paper Series, No. 99.

28. Revill P, Walker S, Madan J, et al. Using cost-effectiveness thresholds to determine value for money in low-and middle-income country healthcare systems: Are current international norms fit for purpose? York: Centre for Health Economics, University of York, 2014. CHE Research Paper Series, No. 98. 